\title{
COVID-19: The Level of Knowledge, Anxiety and Symptom Presentation
}

\author{
Kemal Kef $\mathbb{D}$ \\ Private Kesan Hospital, Department of \\ ENT, Edirne, Turkey
}

\begin{abstract}
Objective: This study aims to establish whether there is a relationship between the level of knowledge about COVID-19, anxiety scores, and pseudo increases in the symptoms of the patients or not.

Methods: The Beck Anxiety Inventory (BAI) and Republic of Turkey Ministry of Health General Directorate's COVID-19 (SARS-CoV-2 infection) General Information, Epidemiology, and Diagnosis Guide were reviewed to generate the questionnaire's content. The data were obtained through a face-to-face interview method. To test their level of knowledge about COVID-19, they were asked multiple-choice questions that have one or more possible right answers. The Statistical Package for Social Sciences was used for statistical analysis. The results were presented as mean and standard deviations for numerical variables and as frequency and percentage for categorical data.

Results: A total of 402 patients were included in this questionnaire-based study. The average age of the patients was $44.67 \pm 4.95$ years, and $204(50.7 \%)$ of them were female. The average anxiety score according to the BAI was $7.98 \pm 1.29$ which classifies as mild anxiety. The overall responses for the knowledge level on COVID-19 section are presented in Table 2. The average score was $9.2 \pm 2.7$ points out of a possible 14 .

Conclusion: The study population showed a moderate level of knowledge, and on average, the patients were not very anxious about the outbreak. The psychosomatic effects of the anxiety caused by the pandemic should be kept in mind by the clinicians since the patients might require a psychiatric consultation in the treatment process.
\end{abstract}

Keywords: COVID-19, anxiety, knowledge level, symptoms

\section{Introduction}

Coronaviruses (CoVs) are single-stranded positive-sense enveloped RNA viruses belonging to the Coronaviridae family. ${ }^{1} \mathrm{CoVs}$ comprise five members; HCoV229E, HCoV-OC43, HCoV-NL63, HKU1-CoV, and SARS-CoV. ${ }^{1}$ Alpha, beta, gamma, and delta primary sub-groups were identified in CoVs. ${ }^{2}$ Most of the Coronavirus $(\mathrm{CoV})$ types can be found in humans, bats, swine, pets, poultries, and rodents. ${ }^{1}$ Human species infection and human-to-human transmission can be seen among the CoV subtypes that cause a mild form of the common cold. ${ }^{3}$ Besides, the Middle East respiratory syndrome-related coronavirus (MERS-CoV) and severe acute respiratory syndrome-related coronavirus (SARS-CoV) are the members of the same virus family that appeared as more severe and fatal causes of infections. ${ }^{2,3}$ Some CoV subtypes with clinical pictures that showed severe infections can be zoonotic and cause infections in humans. ${ }^{1}$ In Turkey, CoVs cause common, self-limiting, and mild forms of infections during the autumn season.
Correspondence: Kemal Kef Private Kesan Hospital, Department of ENT, Edirne, Turkey

Tel +90532 70I 7086

Email dr.kemalkef@gmail.com 
In 2003, a new human respiratory disease, SARS-CoV, emerged that threatened the whole world with lethal infections (11\% fatality rate). ${ }^{3}$ In 2012, the World Health Organization (WHO) issued a global disease MERS-CoV that was named after the region of the first known case, the Kingdom of Saudi Arabia. ${ }^{4}$ The fatality rate was $35-50 \%$ for MERS-CoV. ${ }^{2,4}$ Origin of SARS-CoV cases was linked to Himalayan palm civet cat, and MERS-CoV cases were linked to dromedary camels that infected humans via an interspecies transmission. ${ }^{1,4}$ On December 31, 2019, the WHO Chinese Country Office reported pneumonia cases with unknown etiologies in the Wuhan City, precisely in the Chinese wholesale fish and live animal market. ${ }^{5}$ Chinese government isolated and identified the novel coronavirus, and declared the source location of this virus as a wholesale seafood market. In regard to the Coronavirus Study Group, the virus was identified as SARS-CoV-2 for taxonomic relations to SARS-CoV, and Coronavirus Disease-19 (COVID-19) was introduced by WHO as the name of the current outbreak. ${ }^{6}$ Airborne (droplets and aerosols) transmission was found to be the most virulent route for spreading interhuman transmission. ${ }^{1,7}$ As a result of hand contact with the viruses spread by the patients, the virus can enter the body from the mucosae due to excessive touching to the eyes, noses, and mouths with unsanitized hands. The viruses settle and multiply in the lungs, forming the clinical infection. ${ }^{3}$ On January 30, 2020, WHO announced that the COVID-19 outbreak was an international public health emergency, and then WHO has declared that it was a pandemic disease since 11 March 2020 due to high rates of spread and fatality.

On March 10, 2020, the first case of COVID-19 was confirmed in Turkey. ${ }^{8}$ The rapid spread of the outbreak, its severe course, causing dyspnea, the need for intensive care, and causing deaths (estimated data $0.91 \%$ ) have created serious anxiety and panic amongst the Turkish population likewise the rest of the world. ${ }^{8,9}$ This situation generated a new term: Coronamania (excessive protection, detaching from society, and extreme use of disinfection methods). ${ }^{10}$ The rapid transmission of the disease forced people to keep themselves in isolation at their homes, and lack of social connections resulted in bad emotional well-being, which is also damaging to physical-health. ${ }^{11}$ To decrease confirmed cases, each country took some precautions such as travel restrictions, pausing production, closure of educational institutions, etc. which impacted socio-economic states negatively. ${ }^{12}$ As a result of socio-economic problems and loss of health (or fear of losing health), post-trauma-like psychological reactions become more frequent and turn into a mental outbreak in people who experience fear, desperation, depression, and fear of dying. ${ }^{9,13}$ Park et $\mathrm{al}^{14}$ found similar results on the state of mental health in a study conducted on nurses who worked in hospitals during a MERS-CoV outbreak.

The continuous coronavirus posts in the visual media and on social media sites have increased anxiety and panic. Sahu et $\mathrm{al}^{15}$ referred to the problem as an "infodemic" and pointed out that the evergrowing usage of social media platforms are amplifying the problem. A study by Saravanan et al ${ }^{16}$ stated students who exhibited anxiety concerning COVID-19 anxiety and fear, and who spent more than 4 hours reading about COVID-19 were more psychologically distressed. Above all, people who were diagnosed with obsessive-compulsive disorder, borderline personality disorder, and narcissistic personality disorder may experience severe anxiety, fear, helplessness, desperation, hopelessness, feeling of worthlessness, and even psychosis. ${ }^{17-19}$ On those who have no psychiatric diagnosis; anxiety, fear of death, and depression rates have increased. ${ }^{19,20}$

People may experience their simple symptoms more exaggerated and catastrophize the possible outcomes. The anxiety caused by the risk of infection and death can be more serious in the elderly and would require immediate attention. $^{21}$

In the otorhinolaryngology clinic, some patients tend to express their complaints such as sore throat, dysphagia, tinnitus, loss of hearing, loss of taste, loss of smell, and dizziness exaggeratedly due to anxiety. Those complaints generally do not match with the physicians' findings and they might be called pseudo-symptoms. This study aims to establish whether there is a relationship between the level of knowledge about COVID-19, anxiety scores, and pseudo increases in the symptoms of the patients or not.

\section{Materials and Methods Study Design and Sample Size}

The research was carried out between September 1 and 30 with 402 voluntary patients. Patients were asked to fill BAI out by themselves to avoid affecting their answers since it is a self-reported questionnaire. However, the questions about the knowledge on COVID-19 were obtained through a faceto-face interview method. Informed consent was obtained from all of the participants. Patients' gender and age were recorded by their verbal statements. Patients who have been admitted to the otorhinolaryngology clinic without COVID19 related complaints were asked to attend the survey. The study was conducted during the clinic hours in the Turkish 
language via the certified healthcare professional in charge. The inclusion criteria were being over 18 years old and being admitted to the the otorhinolaryngology clinic without COVID-19 related complaints. The exclusion criteria were being younger than 18 years of age, history of present or past COVID-19 infection, and having a clinic consultation considering a specialty other than otorhinolaryngology.

The Beck Anxiety Inventory (BAI) and Republic of Turkey Ministry of Health General Directorate's COVID19 (SARS-CoV-2 infection) General Information, Epidemiology, and Diagnosis Guide were reviewed to generate the questionnaire's content. ${ }^{22,23}$ It is a descriptive study using a questionnaire consisting of 30 questions which were composed of three groups: the BAI (questions 1-21), survey to analyze knowledge level on COVID-19 (questions 22-28), and self-evaluation survey (questions 29.30). The overall questionnaire is shown in Table 1. In the first section, each answer was scored on a scale of 0 (not at all) to 3 (severely). The total possible score is 63 , and the scale interval is as follows: 0-7 minimal, 8-15 mild, 16-25 moderate, and 26-63 severe. Patients were asked to carefully read each item and indicate how much they have been bothered by that symptom. To test their level of knowledge about COVID-19, they were asked multiple-choice questions that have one or more possible right answers. Each right answer is counted as 1 point, and the highest possible score is 14 . The last section made them examine their current state of mind considering COVID-19 by questioning their estimated risk of getting infected and symptoms that they had lately. The patients who showed symptoms were additionally examined by physicians to evaluate whether there is a pseudo increase connected to anxiety or not.

\section{Ethics Approval}

This descriptive study was approved by the Ministry of Health Scientific Research Committee, protocol code: 2020-08-03T21.

\section{Data Analysis}

The data were analyzed with IBM SPSS Statistics, Version 23.0. Armonk, NY: IBM Corp. The normality of the data was screened using the Shapiro-Wilk test. The categorical data were expressed as numbers and percentages. Normally distributed variables (age and average scores) were stated as mean \pm standard deviation. The Pearson Correlation coefficient was used to measure the relationship between the anxiety scores, COVID-19 related knowledge level, self-assessed infection risk, and symptoms patients showed in the last 3 months. A p-value $<0.05$ was set for statistical significance.

\section{Results}

A total of 402 patients were included in this questionnairebased study. The average age of the patients was $44.67 \pm 4.95$ years, and $204(50.7 \%)$ of them were female. The average anxiety score according to the BAI was $7.98 \pm 1.29$ which classifies as mild anxiety.

Table I The Questionnaire Used in the Study

\begin{tabular}{|l|l|}
\hline Questions & Answers \\
\hline I-2I) The BAI & Not at all/Mildly/Moderately/Severely \\
\hline 22) Incubation period & $0-$ I days/2-I4 days/I5-2I days/Over 22 days/No idea \\
\hline 23) Risk groups & Aged 65+ yearsComorbidity/lmmunosuppressed patients/Healthcare workers/aged 0-I9 years \\
\hline 24) Main route of transmission & Droplet/Airborne/Direct contact/Oral/No idea \\
\hline 25) Symptoms & Shortness of breath/High fever/Dry cough/Chest pain/Wet cough \\
\hline 26) Prevention & Social distance/Mask/Airing out the house/Traditional cologne water/Alcohol based antiseptics/Disposable gloves \\
\hline 27) Social distance & Less than I meter/At least I.5 meters/More than 3 meters \\
\hline 28) People who need to wear a mask & $\begin{array}{l}\text { People with a sickness/People who might be sick/People who are in contact with sick people/Healthy people/ } \\
\text { Healthcare workers/Others }\end{array}$ \\
\hline 29) Your risk of catching COVID-I9 & $0-20 \% / 2$ I-40\%/4I-60\%/6I-80\%/8I-I00\% \\
\hline $\begin{array}{l}\text { 30) Symptoms you have had in last } \\
\text { 3 months }\end{array}$ & $\begin{array}{l}\text { Loss of smell/Loss of taste/Tinnitus/Vertigo/Loss of hearing/Headache/Dysphagia/Numbness and tingling in } \\
\text { face/Others/None }\end{array}$ \\
\hline
\end{tabular}

Note: The participants were able to choose more than one option for the $23 \mathrm{rd}, 25$ th, 26th, 28th, and 30 th questions. 
The overall responses for the knowledge level on COVID-19 section are presented in Table 2. The average score was $9.2 \pm 2.7$ points out of a possible 14 . Of the patients, $91.8 \%$ stated that $2-14$ days is the incubation

Table 2 Responses for the Level of Knowledge About COVID19 Questions

\begin{tabular}{|c|c|}
\hline & Patients [n (\%)] \\
\hline Incubation period & \\
\hline $0-1$ days & $16(4.0)$ \\
\hline $2-14$ days & $369(91.8)$ \\
\hline$|5-2|$ days & $6(1.5)$ \\
\hline Over 22 days & $6(1.5)$ \\
\hline No idea & $5(1.2)$ \\
\hline Risk groups & \\
\hline Aged $65+$ years & $381(94.8)$ \\
\hline Comorbidity & $287(71.4)$ \\
\hline Immunosuppressed patients & $24 \mid(60.0)$ \\
\hline Healthcare workers & $158(39.3)$ \\
\hline Aged 0-19 years & $83(20.6)$ \\
\hline Main route of transmission & \\
\hline Droplet & $|7|(42.5)$ \\
\hline Airborne & $117(29.1)$ \\
\hline Direct contact & $92(22.9)$ \\
\hline Oral & $19(4.7)$ \\
\hline No idea & $3(0.7)$ \\
\hline Symptoms & \\
\hline Shortness of breath & $378(94.0)$ \\
\hline High fever & $387(96.3)$ \\
\hline Dry cough & $328(8 I .6)$ \\
\hline Chest pain & $84(20.9)$ \\
\hline Wet cough & $27(6.7)$ \\
\hline Prevention & \\
\hline Social distance & $382(95.0)$ \\
\hline Mask & $364(90.5)$ \\
\hline Airing out the house & $229(57.0)$ \\
\hline Traditional cologne water & $256(63.7)$ \\
\hline Alcohol based antiseptics & $187(46.5)$ \\
\hline Disposable gloves & $118(29.4)$ \\
\hline Social distance & \\
\hline Less than I meter & $7(1.74)$ \\
\hline At least 1.5 meters & $379(94.28)$ \\
\hline More than 3 meters & $16(3.98)$ \\
\hline People who need to wear a mask & \\
\hline People with a sickness & $379(94.3)$ \\
\hline People who might be sick & $350(87.1)$ \\
\hline People who are in contact with sick people & $352(87.6)$ \\
\hline Healthy people & $340(84.6)$ \\
\hline Healthcare workers & $35 \mathrm{I}(87.3)$ \\
\hline Others & $53(13.2)$ \\
\hline
\end{tabular}

period. Being $65+$ years old, having comorbidity, and being an immunosuppressed patient generate the main risk groups of COVID-19. One hundred seventy-one $(42.5 \%)$ of them defended droplet transmission is the most virulent route for infection. Only $3(0.7 \%)$ of them had no idea on the main route of transmission. Shortness of breath, high fever, and dry cough were the most common answers to the question of symptoms. Social distance $(\mathrm{n}=382,95.0 \%)$ followed by mask $(\mathrm{n}=364,90.5 \%)$ were the most selected prevention methods. The most common opinion about the social distance was at least 1.5 meters (94.28\%). To the question of who needs to wear a mask for protection, participants defended all the answers, each with high percentages, with the exception of "others" as an option.

The majority of patients (35.6\%) thought that they had a $0-20 \%$ risk of catching COVID-19 infection which was the lowest risk option (Table 3). Only 35 (8.7\%) of them thought that $81-100 \%$ was their-risk of being infected. One hundred and thirty-six (33.8\%) patients reported no symptoms to the question of which symptoms you have had in the last 3 months. However, 123 (30.6\%) of them experienced loss of hearing, and $111(27.6 \%)$ of them had experienced vertigo.

According to Table 4, the anxiety scores were not significantly correlated with information levels; however, the anxiety scores showed a positive correlation with the risk of infection

Table 3 Responses for the Self-Assessed Infection Risk, and Symptoms Patients Showed in the Last 3 Months Questions

\begin{tabular}{|l|l|}
\hline & Patients [n (\%)] \\
\hline Your risk of catching COVID-19 & \\
$0-20 \%$ & $143(35.6)$ \\
$21-40 \%$ & $126(31.3)$ \\
$41-60 \%$ & $68(16.9)$ \\
$61-80 \%$ & $30(7.5)$ \\
$81-100 \%$ & $35(8.7)$ \\
\hline Symptoms you have had in last 3 months & \\
Loss of smell & $7(1.7)$ \\
Loss of taste & $5(1.2)$ \\
Tinnitus & $62(15.4)$ \\
Vertigo & $111(27.6)$ \\
Loss of hearing & $123(30.6)$ \\
Headache & $57(14.2)$ \\
Dysphagia & $14(3.5)$ \\
Numbness and tingling in face & $4(1)$ \\
Others & $55(11.7)$ \\
None & $136(33.8)$ \\
\hline
\end{tabular}


Table 4 The Pearson Correlation Analysis

\begin{tabular}{|l|l|l|l|l|}
\hline & $\mathbf{I}$ & $\mathbf{2}$ & $\mathbf{3}$ & $\mathbf{4}$ \\
\hline I. Anxiety scores & - & & & \\
2. Information levels & -0.051 & - & & \\
3. Risk of infection & $0.679 *$ & -0.124 & - & \\
4. Symptoms & $0.627^{*}$ & -0.089 & $0.548^{*}$ & - \\
\hline
\end{tabular}

Note: *Correlation is significant at the $0.00 \mathrm{I}$ level (2-tailed).

and symptoms $(r=0.679, \mathrm{p}<0.001$, and $\mathrm{r}=0.627, \mathrm{p}<0.001$, respectively). Also, there was a positive correlation between the risk of infection and symptoms $(r=0.548, \mathrm{p}<0.001)$.

\section{Discussion}

The current pandemic of COVID-19 is a worldwide health problem besides its socio-economic impacts. Since the first confirmed case in Turkey, many facilities stopped offering services, social connections decreased, and people got affected both physically and emotionally. ${ }^{11,12}$ The accurate knowledge acquisition and maintaining psychological well-being gained prominence to survive with minimum or no damage from the outbreak. Therefore, measuring awareness, anxiety, and self-risk assessments of the patients are essential for action planning, and identifying patient groups. By this, physicians will be able to know if patients were informed about COVID-19 adequately and decide whether there is a pseudo increase in their presented symptoms by evaluating their anxiety levels.

In this study, we investigated patients' anxiety levels by questioning their approach to nervousness, dizziness or lightheadedness, hands trembling, and fear of dying symptoms with a scale. For all the symptoms, the option "severely experienced" was the least selected. The cluster was on the "not at all" option, which indicates patients who were admitted to the otorhinolaryngology clinic during the outbreak had minimal existing anxiety findings. The average anxiety score was $7.98 \pm 1.29$ which classifies as mild anxiety. However, there were 7 (1.74\%) outliers; 5 patients had an anxiety score between 16 and 25 (moderate) and 2 patients had a score between 26 and 63 (severe). Those patients were referred to the psychiatry clinic for consultation.

The anxiety levels could have been caused by the increasing mortalities in Turkey during the data collection process. The reports by the Turkish Ministry of Health show a $69.3 \%$ increase (347 deaths as opposed to the previous week's205) in the mortality caused by the infection during the first week of September. The mortality caused by the infection continued to increase throughout the month of September. ${ }^{24}$

In a study conducted by Wang et $\mathrm{al}^{25} 28.8 \%$ of the respondents stated severe anxiety, but the anxiety levels were lower in accurately informed and precaution taking groups. However, we did not find any correlation between anxiety and information levels. On the other hand, if patients thought that they were likely to catch an infection, their anxiety scores showed an increase. This supports the previous COVID-19 study about risk perception and anxiety. $^{26}$

In light of the average score obtained from COVID-19related questions, the knowledge level among the patients can be presented as moderate. The COVID-19 knowledge score of $10.8 \pm 1.6$ out of 12 was detected in another study which shows a higher rate of knowledge among the Chinese general population. ${ }^{27}$ The authors stated that their study sample was composed of a well-educated population and their information channels were very active even during the very early stages of the outbreak. This may explain the higher rate of knowledge compared to our study composed of patients from the general population.

In our study, only $42.5 \%$ of the patients stated that infection spreads mainly via respiratory droplets while in a Chinese population-based study, $97.8 \%$ of them knew that it spreads via droplets. ${ }^{27}$ When the question was about symptoms, populations showed similar knowledge levels. $^{10,28}$ In a study conducted by Ferdous et $\mathrm{al}^{28}$ $91.3 \%$ of the population defended 2-14 days for the incubation period, which is coherent with our findings. On prevention, both populations think that maintaining social distance and wearing masks are the main methods. ${ }^{25}$ Being older than 65 years old and having a comorbidity were the most reported risk group options which are in accordance with the literature. ${ }^{28}$

In the context of COVID-19, we observed that the majority of patients agreed on the necessity of wearing a mask for a variety of scenarios. The cluster was on the people with an illness section while the other alternatives also had supporters more than $85 \%$. Knowing the universal masking decreased the number of cases and reduced community transmission might be the reason for this. ${ }^{29}$ Meanwhile, Feng et al ${ }^{29}$ highlight the supply shortage of masks and recommend healthy people using masks rationally, and avoiding crowded areas. The patient group in our study is conscious of this social distance regulation and by leaving at least 1.5 meters space $(94.28 \%)$, they help to 
reduce the density of the crowd. With the combination of widely used masks and social distance, they can prevent droplet infection.

Approximately, one-third of our participants had no symptoms in the past 3 months. Accordingly, they estimated their risk of catching COVID-19 as 0-20\%. Anxiety increase is often seen in groups who discern high infection risk, and our study showed that it also correlates highly with having a symptom. ${ }^{26}$ Additionally, symptoms and perception of COVID-19 risk are found to be correlated in our study (Table 4).

The study by Luo et $\mathrm{al}^{30}$ has stated a higher risk of mental health and anxiety problems in females. They have explained that the social factors and gender roles in a community could be the determining factor in this result. Whereas we have no scientifically significant difference in between genders regarding neither knowledge nor anxiety levels. The demographics of the study region could be further investigated to provide a better understanding of the reasons behind this indifference.

Tee et $\mathrm{al}^{31}$ have compared seven different middleincome countries in Asia and they have found similar risk factors for adverse mental health status. The protecting factors they have established also seemed to be similar within the seven countries. Their study supports the role of social, economic and geographic factors on mental health.

The reason for not finding any significant correlation between anxiety and information levels is hypothesized to be the way the information is presented and the way the patients analyze it. For example, one patient could be not interested in COVID-19 and their level of anxiety and knowledge would be low, whereas an anxious but uninformed (or misinformed) patient could have low levels of "correct" knowledge but high levels of anxiety. The opposite can be said about correctly informed patients. One well-informed patient could analyze the risks of the pandemic and could adjust their anxiety levels with proper precautions where as another well-informed patient with an anxious character could be overwhelmed by the information.

This hypothesis could be supported by the aforementioned study conducted by Saravanan et $\mathrm{a}^{16}$ and the "infodemic". There are also researches conducted upon physicians. Even though the level of knowledge about COVID-19 amongst physicians is higher than the general public they may still present high levels of anxiety. ${ }^{32-35}$ The anxiety of the physicians were caused by their higher estimated risk of getting infected, which is complementary to our results. However, Amin et $\mathrm{al}^{32}$ and Sancak et $\mathrm{al}^{33}$ compared the knowledge levels of physicians amongst themselves instead of the general public and they found a positive relationship between lower levels of knowledge and anxiety. A more detailed explanation of sociodemographic variables is needed and they should be evaluated in further studies.

Our study has several limitations. The studied group was composed of patients who had no COVID-19 related medical histories; however, anxiety-related symptoms were found in SARS-CoV survivors, which raise the need for further studies for COVID-19 survivors with our study design. ${ }^{9}$ Jeong et $\mathrm{al}^{36}$ compared MERS patients with the isolated people and found a significantly higher presentation of the related symptoms. Although the results seem obvious at first, a comparison could be made in terms of presentation of symptoms between the patients who are not infected with the COVID-19 virus that have high levels of anxiety and COVID-19-infected patients in our study. Considering the high asymptomatic patient ratios of the current pandemic, this comparison could create greater understanding of the role of anxiety in experiencing symptoms. Also, this study is limited to the people who have been admitted to the otorhinolaryngology clinic so future research can include a larger sample from different departments.

In conclusion, our study population showed a moderate level of knowledge, and on average, the patients were not very anxious about the outbreak. By evaluating anxiety levels, physicians can have a better understanding of the patients' risk perception and whether they have a pseudo rise in their symptoms caused by COVID-19 concerns. The psychosomatic effects of the anxiety caused by the pandemic should be kept in mind by the clinicians since the patients might require a psychiatric consultation in the treatment process.

\section{Data Sharing Statement}

The statistical data used to support the findings of this study are available online at https://docs.google.com/spreadsheets/d/ 1JCEKD5ROMUDjcK5GmhBINerrnWsVMisqTZ2Myd55g $w E / e d i t ? u s p=$ sharing.

\section{Ethical Approval}

This descriptive study was approved by the Ministry of Health Scientific Research Committee, protocol code: 2020-08-03T21. The procedures followed were in accordance with the ethical standards of the responsible 
committee on human experimentation and with the Helsinki Declaration of 1975.

\section{Consent}

Written informed consent was obtained from all the study participants. The explicit written consent of the participants whose photographs are used in the paper was obtained.

\section{Acknowledgment}

The authors thank the surveyor and participant students for their cooperation in the data collection and Irmak Özyiğit for her assistance throughout the study.

\section{Funding}

No funding was received for this study. The expenses were met by the author.

\section{Disclosure}

The author declared no potential conflicts of interest with respect to this work, the research, authorship, and/or publication of this article.

\section{References}

1. Mahony JB. Coronaviruses. In: Murray PR, Baron EJ, Jorgensen JH, Landry ML, Pfaller MA, editors. Manual of Clinical Microbiology. Washington: ASM Press; 2007:1414-1423.

2. Li G, Fan Y, Lai Y, et al. Coronavirus infections and immune responses. J Med Virol. 2020;92(4):424-432. doi:10.1002/jmv.25685

3. Cavanagh D. Coronaviruses and toroviruses. In: Zuckerman AJ, Banatvala JE, Pattison JR, Griffiths PD, Schoub BD, editors. Principles and Practice of Clinical Virology. Chichester: John Wiley and Sons LTD; 2004:379-397.

4. World Health Organization. WHO MERS global summary and assessment of risk; January 21, 2020. [Epub ahead of print.]

5. World Health Organization. Pneumonia of unknown cause - China; 2020 (cited October 11, 2020). Available from: https://www.who.int/ csr/don/05-january-2020-pneumonia-of-unkown-cause-china/en/. Accessed April 22, 2021.

6. Gorbalenya AE. The species severe acute respiratory syndrome related coronavirus: classifying 2019-nCoV and naming it SARS-CoV-2. Nat Microbiol. 2020;5:536-544.

7. Zhang R, Li Y, Zhang AL, et al. Identifying airborne transmission as the dominant route for the spread of COVID-19. Proc Natl Acad Sci USA. 2020;117(26):14857-14863. doi:10.1073/pnas.2009637117

8. Hasöksüz M, Kılı̨̧ S, Saraç F. Coronaviruses and SARS-COV-2. Turk J Med Sci. 2020;50(SI-1):549-556. doi:10.3906/sag-2004-127

9. Wu KK, Chan SK, Ma TM. Posttraumatic stress, anxiety, and depression in survivors of severe acute respiratory syndrome (SARS). J Trauma Stress. 2005;18(1):39-42. doi:10.1002/jts.20004

10. Ünal S. A psychosocial evaluation about the COVID-19 pandemic in the context of the terror management theory. Klin Psikiyatr Derg. 2020;23(1):67-71.

11. Lunstad JH. The potential public health relevance of social isolation and loneliness: prevalence, epidemiology, and risk factors. Public Policy Aging Rep. 2017;27(4):127-130. doi:10.1093/ppar/prx030
12. Nicola M, Alsafi Z, Sohrabi C, et al. The socio-economic implications of the coronavirus pandemic (COVID-19): a review. Int J Surg. 2020;78:185-193. doi:10.1016/j.ijsu.2020.04.018

13. Pfefferbaum B, North CS. Mental health and the Covid-19 pandemic. $N$ Engl J Med. 2020;383(6):510-512. doi:10.1056/ NEJMp2008017

14. Park JS, Lee EH, Park NR, et al. Mental health of nurses working at a government-designated hospital during a MERS-CoV outbreak: a cross-sectional study. Arch Psychiatr Nurs. 2018;32(1):2-6. doi:10.1016/j.apnu.2017.09.006

15. Sahu KK, Kumar R. Preventive and treatment strategies of COVID-19: from community to clinical trials. J Family Med Prim Care. 2020;31(5):2149-2157. doi:10.4103/jfmpc.jfmpc_728_20

16. Saravanan C, Mahmoud I, Elshami W, Taha MH. Knowledge, anxiety, fear, and psychological distress about COVID-19 among university students in the United Arab Emirates. Front Psychiatry. 2020;11:1057. doi:10.3389/fpsyt.2020.582189

17. Ferrando SJ, Klepacz L, Lynch S, et al. COVID-19 psychosis: a potential new neuropsychiatric condition triggered by novel coronavirus infection and the inflammatory response? Psychosomatics. 2020;61(5):551-555. doi:10.1016/j.psym.2020.05.012

18. Chacko M, Job A, Caston F, et al. COVID-19-induced psychosis and suicidal behavior: case Report. SN Compr Clin Med. 2020;26:1-5. doi:10.1007/s42399-020-00530-7

19. Serafini G, Parmigiani B, Amerio A, et al. The psychological impact of COVID-19 on the mental health in the general population. QJM. 2020;113(8):531-537. doi:10.1093/qjmed/hcaa201

20. Le HT, Lai AJX, Sun J, et al. Anxiety and depression among people under the nationwide partial lockdown in Vietnam. Front Public Health. 2020;8:589359. doi:10.3389/fpubh.2020.589359

21. Aki ÖE. Covid-19 pandemic and the mental health of elderly. Turk J Geriatri. 2020;23(3):291-298. doi:10.31086/tjgeri.2020.165

22. Ulusoy M, Şahin NH, Erkmen H. Turkish version of the beck anxiety inventory: psychometric properties. J Cogn Psychother. 1998;12 (2):163-172.

23. The Republic of Turkey Ministry of Health, Directorate General of Public Health. COVID-19 general information, epidemiology and diagnosis. COVID-19 (SARS-CoV-2 Infection) guide; 2020 May.

24. Ministry of Health. "COVID durum raporu." (COVID Reports) T.C. Sağlık Bakanlığı COVID-19 bilgilendirme Platformu; 2020. Available from: https://covid19.saglik.gov.tr/TR-68443/covid-19durum-raporu.html. Accessed April 22, 2021.

25. Wang C, Pan R, Wan X, et al. Immediate psychological responses and associated factors during the initial stage of the 2019 coronavirus disease (COVID-19) epidemic among the general population in China. Int $J$ Environ Res Public Health. 2020;17(5):1729. doi:10.3390/ijerph17051729

26. Petzold MB, Bendau A, Plag J, et al. Risk, resilience, psychological distress, and anxiety at the beginning of the COVID-19 pandemic in Germany. Brain Behav. 2020;10:e01745.

27. Zhong BL, Luo W, Li HM, et al. Knowledge, attitudes, and practices towards COVID-19 among Chinese residents during the rapid rise period of the COVID-19 outbreak: a quick online cross-sectional survey. Int $J$ Biol Sci. 2020;16(10):1745-1752. doi:10.7150/ ijbs. 45221

28. Ferdous MZ, Islam MS, Sikder MT, et al. Knowledge, attitude, and practice regarding COVID-19 outbreak in Bangladesh: an online-based cross-sectional study. PLoS One. 2020;15(10): e0239254. doi:10.1371/journal.pone.0239254

29. Feng S, Shen $\mathrm{C}$, Xia N, et al. Rational use of face masks in the COVID-19 pandemic. Lancet. 2020;8(5):434-436. doi:10.1016/ S2213-2600(20)30134-X

30. Luo Y, Chua CR, Xiong Z, Ho RC, Ho CSH. A systematic review of the impact of viral respiratory epidemics on mental health: an implication on the coronavirus disease 2019 pandemic. Front Psychiatry. 2020;11:565098. doi:10.3389/fpsyt.2020.565098 
31. Tee $\mathrm{M}$, Wang $\mathrm{C}$, Tee $\mathrm{C}$, et al. Impact of the COVID-19 pandemic on physical and mental health in lower and upper middle-income Asian countries: a comparison between the Philippines and China. Front Psychiatry. 2020;11:568929. doi:10.3389/fpsyt.2020.568929

32. Amin F, Sharif S, Saeed R, Durrani N, Jilani D. COVID-19 pandemic- knowledge, perception, anxiety and depression among frontline doctors of Pakistan. BMC Psychiatry. 2020;20(1):459. doi:10.1186/s12888-020-02864-x

33. Sancak B, Ozer U, Kilic C, Sayar GH. Covid-19-related anxiety levels in physicians: a preliminary study. Düşünen Adam. 2020;33:366-375. doi:10.14744/DAJPNS.2020.00105
34. Uyaroğlu OA, Başaran NÇ, Ozisik L, et al. Evaluation of the effect of COVID-19 pandemic on anxiety severity of physicians working in the internal medicine department of a tertiary care hospital: a cross-sectional survey. Intern Med J. 2020;50(11):1350-1358. doi:10.1111/imj.14981

35. Kaya Y, Bostan S, Düğeroğlu H, Özbilen M, Keskin H. The effect of COVID-19 pandemic on the anxiety levels of internal medicine physicians and practise of internal medicine clinics. J Int Health Sci Manag. 2020;6(12):8-13. doi:10.48121/jihsam.772710

36. Jeong H, Yim HW, Song YJ, et al. Mental health status of people isolated due to Middle East respiratory syndrome. Epidemiol Health. 2016;38:e2016048. doi:10.4178/epih.e2016048

\section{Publish your work in this journal}

Psychology Research and Behavior Management is an international, peer-reviewed, open access journal focusing on the science of psychology and its application in behavior management to develop improved outcomes in the clinical, educational, sports and business arenas. Specific topics covered in the journal include: Neuroscience, memory and decision making; Behavior modification and management; Clinical applications; Business and sports performance management; Social and developmental studies; Animal studies. The manuscript management system is completely online and includes a very quick and fair peer-review system, which is all easy to use. Visit http://www. dovepress.com/testimonials.php to read real quotes from published authors. 